\title{
Constructing and Protecting Identity in a Diverse Higher Education Context
}

\author{
Rusi Jaspal \\ De Montfort University Leicester
}

\begin{abstract}
UK higher education (HE) has become increasingly diverse. Despite the clear social, economic and pedagogical benefits of diversity, it can also be challenging for identity as it may bring about psychological change and compel both the "dominant majority" and "minorities" to adjust to the presence, identities and worldviews of the other. Drawing upon Identity Process Theory from social psychology, the present article explores the potential challenges to identity in a diverse HE context and how students may subsequently cope with these challenges. After a brief overview of Breakwell's (1986) Identity Process Theory, two case studies are presented, namely how social class and ethnic/religious diversity can impact identity. The more general aim of this article is to develop the basic tools for enhancing students' learning experience in a diverse HE context. It is suggested that HE institutions need to support students from diverse backgrounds in ways that are conducive to a positive identity, and that they must facilitate a shared superordinate identity which can be viewed as inclusive and available to all, regardless of class, ethnicity, religion or any other identity.
\end{abstract}

\section{Citing this article}

Jaspal, R. (2015). Constructing and protecting identity in a diverse higher education context. Perspectives: Policy and Practice in Higher Education. 19(4), 27-134. 


\section{Introduction}

UK higher education (HE) has become increasingly diverse - the student population cuts across various social strata, including distinct ethnic, religious, linguistic and socio-economic groups (Buckridge \& Guest, 2007; Savin-Baden, 2000). The UK HE student population has further diversified given the increase in study applications from the emerging economies, such as China and Brazil, as well as growing numbers of students from under-represented groups (e.g. those of distinct socio-economic and ethnic/religious minority backgrounds). While the diversity of $\mathrm{HE}$ is laudable partly due to its enrichment of the learning experience for all learners (Gurin et al., 2002; Niemann \& Maruyama, 2005), identities may also be challenged by diversity as it compels both the "dominant majority" and "minorities" to adjust to the presence, identities and worldviews of the other. This article contributes to contemporary debates surrounding "widening participation" (e.g. McDonough \& Fann, 2007; Thomas, 2002) by exploring the novel angle of how identities may be challenged or enhanced as a result of diversity in HE. More specifically, the aim is to specify the potential social psychological building blocks of a HE context that is conducive to wellbeing and, thus, positive learning among students.

Traditional cognitive theories highlight a series of optimal cognitive conditions for learning and, thus, view mental processes as key in explaining how people learn (e.g. Brown et al., 1989; Sweller et al., 2011). Conversely, social theories of learning tend to emphasise the importance of social and environmental factors in the learning process (e.g. Siemens, 2005; Wenger, 2000). However, these theories have seldom been integrated in research into positive learning in a diverse HE context, which has impeded the development of an integrative framework in which cognition, group membership and society can be collectively examined. Identity has been identified as a key, yet under-explored, construct in theories of pedagogy - fundamentally, people need a positive identity in order to learn effectively (Banks \& McGee Banks, 2005; Bennett, 2003). This is vital because threatened identity -the antithesis of a positive identity - compels the individual to focus their social, psychological and emotional resources on resolving the threat, rather than on learning (Boekaerts, 1993). Drawing upon Identity Process Theory from social psychology, the present article examines the potential challenges to identity in a diverse HE context and how students may subsequently cope with these challenges. After a brief overview of Breakwell's (1986) Identity Process Theory, two case studies are presented, namely how social class and ethnic/religious diversity can impact the identities of students. The building blocks of positive learning should inform policy and practice at the institutional levels, such as student services and personal tutorship, with a view to enhancing the student experience in the context of growing diversity.

\section{Identity Processes: Construction, Threat and Protection}

Identity can be thought of in terms of the unique constellation to self-aspects (that is, sociocognitive categories derived from social experience) that render an individual unique and distinctive. These self-aspects include group memberships (e.g. one's ethnicity or social class) as well as personality traits (e.g. being shy or an extrovert) and physical traits (e.g. body image). The key point is that the individual's identity will be characterised by diversity and multiplicity. Particular self-aspects, such as being a student or a member of an ethnic group, acquire salience in accordance with social context. In order to theorise the potential challenges that diversity in HE may pose to identity, this article draws upon Identity Process Theory (IPT) (Breakwell, 1986; Jaspal \& Breakwell, 2014) from social psychology. IPT examines the construction of identity and, more specifically, how individuals respond to identity threat. It is a framework in which cognition, group membership and society, and their impacts for the individual and their learning, can be collectively examined. By understanding 
these social psychological processes in the context of HE, it may be possible to enhance students' identity construction and their strategies for regulating identity with fruitful and productive outcomes for positive learning.

\section{The Identity Processes}

IPT postulates that people construct identity through engagement with two universal psychological processes:

- assimilation-accommodation - the individual encounters new elements (e.g. becoming a student) which must be assimilated to the existing identity structure, but changes may need to be made to the existing identity structure in order to make room for the addition. For instance, being a factory worker may initially be an important element of identity for an individual, but upon enrolment on her university course she may begin to view herself primarily as a student (rather than as a factory worker). Thus, the accommodation of the student identity may require an attenuation of the factory worker identity.

- evaluation - the individual appends meaning and value to the elements of their identity, new and old. For instance, the university fresher may originally have viewed the factory worker identity as positive because it enabled her to pay her rent, but she may later come to perceive it as negative as it impedes progress on her university course.

These processes are principally cognitive in nature, but the ways in which they function are informed by society (e.g. social norms). How these processes are enacted by the individual will likely change over time. For instance, the factory worker who enrols on an undergraduate course may find that her course is viewed as "a waste of time" by her co-workers who may prioritise "a proper job" over HE (see Hutchings \& Archer, 2001). Conversely, fellow students on her course may collectively speak of the innumerable job opportunities that will arise in the future, which will raise the social status of her student identity. Against this social backdrop, the factory worker-cum-university student will append meaning and value to her student identity.

\section{The Identity Principles}

The two universal processes of identity do not function in a random manner but rather they are guided by identity principles. The identity principles specify the "end-states which are desirable for identity" (Breakwell, 1986, p. 24):

- $\quad$ self-esteem - deriving a sense of self-worth;

- continuity - maintaining a psychological thread between past, present and future in the face of inevitable personal and social change;

- $\quad$ self-efficacy - perceiving competence and control;

- distinctiveness - feeling different and unique;

- belonging - deriving a sense of acceptance and inclusion in relevant groups;

- coherence - establishing a sense of coherence and compatibility between identity elements that are "inter-connected."

It has been shown that those identity elements that satisfy the principles of identity (i.e. those that provide feelings of self-esteem, continuity, self-efficacy and so on) acquire a more central position in the identity structure (Vignoles et al., 2006). Thus, the factory worker who enrols on an undergraduate course may have derived self-efficacy on the basis of her factory worker identity because it enabled her to pay the rent and to support her family financially, but her student identity may subsequently make her feel good about herself (self-esteem), different from others in her occupational community (distinctiveness), and optimistic about her future job prospects (self-efficacy). Therefore, she may come to regard the student 
identity as more central to her self-concept than her factory worker identity. However, the perception that any given identity element serves the identity principles will be determined largely by social factors (Breakwell, 1986). For instance, the factory worker perceives her student identity as enhancing self-esteem, distinctiveness and self-efficacy because other people in the social contexts in which she is embedded see her as special and different and speak of the job opportunities associated with her student identity.

\section{The Coping Strategies}

A key tenet of IPT is that when the processes cannot comply with the aforementioned principles, identity is threatened which is aversive for psychological wellbeing. Social change induced by growing diversity in HE can plausibly challenge identity processes, thereby causing threats to identity. Identity threat can dominate the individual's cognitive processing and engagement with the social world and, thus, impede positive learning (Boekaerts, 1993). However, human beings are agentive and resourceful and, thus, attempt to cope with threats to identity through engagement with strategies functioning at the following levels:

- intrapsychic - the individual may attempt to counteract threat through (i) denial of its presence or of its meanings for identity, (ii) re-conceptualisation of what the threat means for identity, (iii) acceptance of the threat and its implications so that it loses its power to threaten.

- interpersonal - the individual may (i) isolate himself/herself from others, or (ii) contest and counteract the authority of others.

- intergroup - the individual may (i) emphasise those group memberships that minimize threat, (ii) feign membership in a group that one is not really a member of, or (iii) engage in group mobilization/pressure groups.

The coping strategies vary in their level of effectiveness. Deflection strategies, for instance, rely on suppressing cognitions about the threat and tend to be effective only in the short term. Individuals may be cognitively engaged in attempting to suppress the threat (or to deny its existence altogether), which may reduce their cognitive capacity to engage with learning. For instance, knowing that her factory job is not socially valued in the HE context, the former factory worker may re-conceptualise the value of her factory job in the context of her undergraduate career, perhaps by thinking of it as "good career experience", but may find that other students deride her factory job and view this as low status employment. Thus, through contact with others (that is, social contact), her coping strategy of re-conceptualisation may fail and the threat to self-esteem and self-efficacy may re-surface. In this case, the threatened student may decide to drop out and avoid the source of the threat (Thomas, 2002).

Conversely, acceptance strategies, though challenging in the short term, are likely to be successful in the long term because they encourage the assimilation-accommodation of the threatening stimulus and, thus, progress with one's learning. The student may simply accept that her factory job and student identity will not be valued by her fellow students and coworkers, respectively, and cease to expect or hope for positive responses from these groups. These remarks, thus, lose their power to threaten.

It is also noteworthy that the coping strategies may be used in combination in order for the threat to be suppressed. For instance, the factory worker may re-conceptualise the meaning and value of her factory job (i.e. re-conceptualisation) and isolate herself from other students who question this interpretation (i.e. isolation). In this case, the student's positive identity depends on her ability to continue to conceptualise the meaning and value of her factory job in a positive manner. By isolating herself from individuals who may question this interpretation, the individual minimises the possibility of identity threat - she is simply not exposed to information that competes with her re-conceptualisation. However, the perceived need to isolate herself from other students could plausibly interfere with positive learning 
because this might impede class attendance (in a bid to avoid encountering other students) or communication and collaboration with them. This itself may lead to course termination (Thomas, 2002). In the context of a diverse HE, it is necessary to facilitate and encourage coping strategies geared towards acceptance of the threat and adaptation to it. This could be hypothesised to safeguard identity and interpersonal relations in the HE experience, thereby enhancing the learning experience.

\section{Challenges to Identity in the HE Context}

Examples of diversity in UK HE are multifarious. The present section focuses on just two examples, namely how social class and ethnic/religious identities intersect with student identities in the HE context. As two topic areas that have been the focus of previous research into the experience and management of diversity in HE (e.g. Archer et al., 2001; Levin et al., 2009), these case studies are intended to provide fresh insights into the potential antecedents and consequences of threat and coping strategies in HE. This is important because diversity in $\mathrm{HE}$ can pose challenges to identity and induce deflection and disengagement among some students. However, if we are able to understand which aspects of diversity may plausibly threaten identity among students and how they may respond to threat, we will be better positioned to facilitating socially and psychologically healthy coping strategies.

\section{Social Class: Managing Multiple Roles, Responsibilities and Identities}

The issue of social class is controversial, which can be partly attributed to the inherent definitional ambiguities surrounding the concept of "class" as well as the blurred boundaries between distinct social class identities. However, social class has been the focus of several research studies concerning diversity in HE, primarily because it remains a social psychological category to which many students themselves lay claim (e.g. Archer et al., 2001; Ball et el., 2002; Reay et al., 2010).

It is generally acknowledged that students of working-class background are poorly represented in the higher status, so-called 'old' universities, such as the Russell Group universities, and that most are concentrated in the so-called 'post-92' universities (or former polytechnics) (Reay, 2012). This is due partly to the widespread perception among workingclass students that the more elite universities are the preserve of the middle class and, thus, such institutions are "off limits" (Reay et al., 2010; Thomas \& Quinn, 2007). The anticipation of being rejected or excluded by others due to an aspect of one's identity can render salient the belonging principle of identity, and individuals may make choices about university entry based on perceptions of where they are likely to fit in and derive feelings of acceptance and inclusion (Aries \& Seider, 2005; Crozier et al., 2008). However, it is increasingly the case that the elite, as well as the post-92, universities are becoming increasingly diverse, particularly as these institutions make greater attempts to engage diverse sections of the population, including first-generation working-class students (McDonough \& Fann, 2007). While important for safeguarding diversity in $\mathrm{HE}$ and, thus, commendable, this does present potential challenges for identity.

Being the first person in one's family to go to university, as is the case for many working-class students, may mean that the student will experience greater challenges in assimilating and accommodating their student identity in the identity structure. Other elements of their identity may interfere with their student identity. For instance, some working-class students may need to manage multiple role responsibilities during their time as students, such as the competing demands of part-time employment, family responsibilities and their student identities. This can have implications for the coherence principle of identity, given that some of these identities may come to be regarded as conflicting and incompatible. Indeed, in their study of working-class non-participants in HE, Archer et al. (2001) found that 
the interviewees perceived participation in HE as coterminous with "giving up strong working class identities" (p. 443). The two identities were simply not viewed as compatible. Furthermore, students may find little time for their academic studies and their student identity may in turn come to conflict with their occupational identities (Reay et al., 2010). Some may find that they are singled out and judged by others on the basis of one of the two identities, thereby challenging their sense of identity authenticity (see Thomas, 2002).

There may be a lack of understanding in their university and occupational contexts of their occupational and student identities, respectively. Both teachers and fellow students (particularly those who perhaps do not work simultaneously) may, for instance, come to doubt the working-class student's commitment to their academic studies, potentially leading to further marginalisation. Furthermore, it has been noted that some working-class students may feel unable to derive feelings of acceptance and inclusion in predominantly middle-class institutions, in which they may feel excessive distinctiveness (Reay et al., 2010). While many feel that they are of a similar academic standard to other students, they may nonetheless perceive little social solidarity with students of other social class backgrounds (Archer et al., 2001). IPT predicts that individuals may cope by appending greater priority to one group membership over another and, thus, it is foreseeable that some may prioritise their occupational identities and attenuate their student identities (Breakwell, 1986). In this case, the threatened student may begin to distance himself/herself from their student identity and, conversely, immerse himself/herself in their occupational or family identities. While this might provide a temporary escape from threat (facilitated by denial and isolation), it might plausibly induce negative outcomes for their learning.

On the other hand, the stringent pressure to deliver, to meet deadlines and to obtain high grades, may lead some students to immerse themselves in their student identities, sometimes to the detriment of other valued identities (e.g. family or community identities). Moreover, the parents of some working-class students are said to fear that the move away from their close-knit communities (as a result of university enrolment) may amount to "abandoning the family and its norms and values" (Thomas \& Quinn, 2007, p. 63). Although many students do indeed remain committed to their other identities, it is possible that some will shift towards their student identities and attenuate their connection with their family and community identities (Kaufman, 2003). This could challenge the continuity principle of identity, as individuals experience a host of other changes to their everyday lives and social networks, such as loss of previous friendships and relationships outside of the university environment. Of course, an individual has multiple identities which acquire salience in accordance with social context (Deaux \& Ethier, 1994). Students' estrangement from their social networks could result in low social support when this matters most.

These are just some of the social and psychological concerns associated with the social class diversification of UK HE. The list is by no means exhaustive. It is important that UK HE institutions be aware of the potential challenges to the identities of working-class students who remain a minority group in many UK HE institutions, so that appropriate coping strategies can be encouraged.

\section{Ethnic and Religious Diversity in HE: Potentially Competing Perspectives}

In addition to social class diversity, UK HE has become increasingly diverse in terms of ethnicity and religion. In addition to growing representation of British ethnic minority groups in UK HE, in 2012/13, 226,400 EU and international students were enrolled on undergraduate degrees in UK universities. Like social class diversity, ethnic and religious diversity too greatly enriches the HE environment in various ways but it can pose challenges to identity. 
The most obvious challenge to the identities of ethnic and religious minority students includes experiences of prejudice on the basis of their minority identities. There has been some research into prejudice in HE (e.g. Harrison \& Peacock, 2010a, 2010b; Schweisfurth \& $\mathrm{Gu}, 2009$ ). From the perspective of minority students themselves, perceived prejudice can threaten their sense of self-esteem, as they may lose their ability to derive a positive selfconception on the basis of their (often valued) ethnic and religious group memberships (Crocker \& Quinn, 1998). These identities may come to be construed as barriers to full inclusion in the HE environment. Indeed, it has been observed that these identities generally satisfy the identity principles and their stigmatisation can be threatening. Prejudice usually amounts to some form of exclusion, which can deprive the individual of feelings of acceptance and inclusion and, thus, jeopardise the belonging principle of identity. The social desirability of suppressing and concealing their ethnic and religious identities itself may challenge the continuity principle of identity among minorities. Individuals may have appended importance to their ethnic/religious identities but feel that they no longer should in order to be accepted by others, given the undesired rupture between past and present (Breakwell, 1986). Threats to belonging and continuity may induce disengagement from other people who are pivotal in the learning process, as well as a focus upon threat, rather than engagement with learning.

Yet, there is another perspective to the issue of greater ethnic and religious diversity, namely how ethnic and religious majority members respond to growing diversification of an environment that may traditionally have been ethnically and religious homogeneous. In their qualitative interview study of HE students' perceptions of the "internationalization at home" agenda, Harrison and Peacock (2010a) found that home students perceived threats to their future academic success and social identity due to the presence of international students in their academic environment. They argued that efforts should be made to ensure that in the classroom "intercultural encounters are positive, meaningful and non-threatening" (p.897). Diversification entails perceptible social change. This can clearly challenge people's sense of continuity as they may be unaccustomed to seeing, experiencing and interacting with members of ethnic and religious outgroups. If they view others primarily in terms of ethnic and religious difference, growing numbers of outgroup members may well be experienced as threatening to the continuity principle. As ethnic and religious minority students themselves may feel unaccepted and excluded and, thus, choose to associate with fellow ingroup members, this may widen the "gap" between students of distinct ethnic and religious group backgrounds, accentuating intergroup difference and, sometimes, hostility (Peacock \& Harrison, 2010b). Perceived difference and hostility are not conducive to a positive learning environment (DeVita, 2005).

Moreover, intergroup difference and hostility can lead to the development of divergent viewpoints and worldviews with little scope for negotiation and intergroup understanding. A recent ESRC-funded seminar series on LGBT issues in the ESOL classroom has clearly elucidated one of the communicative challenges that can arise as a result of ethnic/religious diversity in education (Nelson, 1999; Wadell et al., 2011). Some ethnic/religious minority students may LGBT identities as wrong, sinful and worthy of condemnation, due to social representations of sexuality that may be associated with their ethnic and religious group memberships (Jaspal, 2015b). Conversely, among ethnic majority Britons in HE contexts, there appears to be growing acceptance of LGBT identities (e.g. Anderson, 2009; Ellis et al., 2003). In his work on sexuality in ESOL, Jaspal (2015a) notes that the suggestion that LGBT identities are not only acceptable but worthy of celebration may be experienced as a threat to people's sense of psychological coherence, because it may challenge their existing views and beliefs concerning sexuality. Conversely, it is plausible that majority members may find ethnic/religious minority students' apparent lack of 
acceptance of LGBT identities unacceptable, leading to disengagement from individuals from these communities. Minority students may in turn feel excluded and, thus, seek acceptance from within their ethnic/religious minority ingroups within the HE context (Rivas-Drake et al., 2008). What ensues is a circular pattern of disengagement, misunderstanding and prejudice, which can impede collaborative activity that is so central to learning in HE. It may be that an optimal coping strategy would be the accentuation of a shared student identity. This has been elegantly described in the Common Ingroup Identity Model (Gaertner \& Dovidio, 2000), which postulates that when individuals categorise themselves and others as part of a higher-level superordinate group, such as being a student (irrespective of their ethnic/religious background), outgroup prejudice will decrease. If students are able to carve out a shared superordinate student identity that takes precedence over, but that does not completely obscure, their ethnic/religious identities, this could satisfy the very principles that are susceptible to threat among majority and minority students alike. For instance, recent work in the US has found that the construction of a common roommate identity may gloss over intergroup differences (Shook \& Fazio, 2008; Trail et al., 2009). On a larger scale, a superordinate university identity has been found to play an important role in establishing links between the various social categories that make up the diverse student body (Levin et al., 2009).

Clearly, the university infrastructure would need to be conducive to a strong university identity, which could be facilitated through intergroup comparison with other universities or through the celebration of ethnic/religious diversity as one of the things that make the university so different from others. This identity would need to be made available to students and students themselves would need to perceive access to, and inclusion in, the superordinate identity. An important motivation for self-identification with any given social category is the perceived extent to which the category provides feelings of self-esteem, selfefficacy, distinctiveness and so on (Vignoles et al., 2002). Thus, the superordinate university identity would need to be one that students feel proud of, that they feel empowers them (possibly through employability), and that makes them feel positively distinguished from others. Given that identities are, to a large extent, socially constructed (Jaspal \& Breakwell, 2014), these aspects of the superordinate university identity would need to be emphasised in order to motivate student identification with it.

\section{Constructing and Protecting Identity: Implications for Learning}

Recent research and commentary on widening participation tends to focus on the potential barriers to HE (Archer et al., 2001; Hutchings \& Archer, 2001) and on the factors that may impact student retention (e.g. Berger \& Braxton, 1998; Ozga \& Sukhnandan, 1998; Thomas, 2002). Conversely, this article, while relevant to these issues, focuses on the social psychological aspects of widening participation, as well as the potential strategies that may be deployed by individuals to cope with social change that this brings about. Some previous research has employed group-level theories in order to demonstrate the social psychological mechanisms underpinning a superordinate identity that can help to reconcile differences among students (e.g. Dovidio et al., 2001; Levin et al., 2009). While this makes a very useful contribution to our understanding of diversity in $\mathrm{HE}$, it does not specify how social change, as a consequence of diversity in $\mathrm{HE}$, may be experienced and responded to by individuals.

Accordingly, Identity Process Theory was introduced as a framework in which cognition, group membership and societal factors might be collectively examined in the context of diversity in HE. It is acknowledged that growing diversity can pose challenges to identity among the diverse groups embedded within these contexts. Some individuals may struggle to embrace a student identity due to their personal and social "histories" and competing identities, roles and responsibilities (Thomas, 2002). Others may themselves find 
it difficult to adjust to change that diversity brings about. Individuals may feel threatened because of growing diversity or the perception that others are unaccepting of such diversity. It should be noted that threat is an aspect of human existence (Breakwell, 1986) - we all experience threat and most of the time we cope with it effectively. However, chronic threats which remain unresolved, or which we try to suppress through the use of deflection strategies, can interfere with our social and psychological functioning, including our learning and academic success (Boekaerts, 1993; Cole et al., 2004).

As highlighted in the examples presented in this article, at a psychological level, individuals may engage in deflection strategies (e.g. Schmader et al., 2002). At an interpersonal level, one may isolate oneself or avoid other learners, essentially hindering learning through collaborative activity. At an intergroup level, one may disassociate oneself from particular groups - either one's ingroup or outgroups - within the HE context. Deflection and disengagement defeat the very object of encouraging and enhancing diversity in HE - we of course learn from other groups, cultures and individuals (Neimann \& Maruyama, 2005). Thus, coping through deflection is unlikely to be effective in the long term. Conversely, learners may be encouraged to deploy more positive (and effective) strategies for coping with threats associated with diversity. These include positive reconstrual of the threat, positive engagement with other individuals under favourable social and psychological circumstances. It is hypothesized that such favourable coping strategies can be encouraged through two principal routes: (i) increasing awareness of the identity challenges faced by diverse groups in HE which may in turn lead to the creation and enhancement of social support networks where they are needed most, and (ii) the construction of an overarching superordinate group identity that can encompass and include the diverse groups that, under some circumstances, can develop tensions and conflicts. Favourable coping strategies of this kind may improve student retention primarily because they empower students (Thomas, 2002).

On a more practical level, student support services should work closely with members of academic and administrative staff to ensure that students from diverse backgrounds are supported in ways that are conducive to a positive identity and, consequently, to positive learning. This support mechanism should be integrated within the identity of the institution so that the institution is perceived by students as one that is genuinely concerned with, and committed to, widening participation in HE. This will require a long-term commitment to widening participation, rather than short-term projects aimed at boosting it. A key method of widening participation is to enhance awareness of its importance primarily through the provision of diversity training, not only to staff members but also to students. This could be integrated in the university curriculum (Gurin et al., 2002), as has also been in the case with "internationalization" agenda, for instance (Harrison \& Peacock, 2010). Moreover, there ought to be a context in which disclosure of identity threat is perceived as possible, so that students' identity concerns can be understood and alleviated when they approach their personal tutors and the university counselling services for assistance. Members of academic staff play a pivotal role in creating social and pedagogical environments in which students of diverse group memberships are able to interact in a pacific and collegiate manner, framing potentially controversial topics (e.g. sexuality) in ways that elicit not evaluative, but objective, statements (Jaspal, 2015a). More generally, in order to create a context in which diversity is valued and celebrated, rather than stigmatized and sidelined, academic staff, support staff and students will collectively need to facilitate a shared superordinate identity which can be viewed as inclusive and available to all, regardless of class, ethnicity, religion or any other identity.

\section{REFERENCES}


Anderson, E. (2009). Inclusive Masculinity: The Changing Nature of Masculinities. New York: Routledge.

Aries, E. \& Seider, M. (2005) The interactive relationship between class identity and the college experience: the case of lower income students, Qualitative Sociology, 28(4), 419442.

Banks, J.A. \& McGee Banks, C.A. (eds.) (2005). Multicultural education: Issues and perspectives. New York: Wiley.

Bennett, C.I. (2003). Comprehensive multicultural education: Theory and practice. Boston: Allyn and Bacon.

Berger, J. B. and Braxton, J. M. (1998) Revising Tinto's interactionalist theory of student departure through theory elaboration: examining the role of organisational attributes in the persistence process, Research in Higher Education, 39 (2), 103-119.

Boekaerts, M. (1993). Being concerned with well-being and with learning. Educational Psychologist, 28(2), 149-167

Breakwell, G.M. (1986). Coping with threatened identities. London: Methuen.

Brown, J.S., Collins, A. \& Duguid, P. (1989). Situated cognition and the culture of learning. Educational Researcher, 18(1), 32-42.

Buckridge, M. and Guest, R. (2007) A conversation about pedagogical responses to increased diversity in university classrooms, Higher Education Research and Development, 26, 133146.

Cole, M.S., Field, H.S. \& Harris, S.G. (2004). Student learning motivation and psychological hardiness: interactive effects on students' reactions to a management class. Academy of Management: Learning and Education, 3(1), 64-85.

Crocker, J. \& Quinn, D. (1998). Racism and self-esteem. In J.L. Eberhardt \& S.T. Fiske (eds.), Confronting racism: The problem and the response (pp.169-187). Thousand Oaks, CA: Sage.

Crozier, G., Reay, D. \& Clayton, J. (2008). Different strokes for different folks: diverse students in diverse institutions. Research Papers in Education, 23(2), 167-177.

Deaux, K.A. \& Ethier, E. (1994). Negotiating social identity when contexts change: maintaining identification and responding to threat. Journal of Personality and Social Psychology, 67(2), 243-51.

De Vita, G. (2005). Fostering intercultural learning through multicultural group work. In J. Carroll \& J. Ryan (Eds) Teaching international students: improving learning for all. Abingdon: Routledge.

Ellis, S., Kitzinger, C. \& Wilkinson, S. (2003). Attitudes towards lesbians and gay men and support for lesbian and gay human rights among psychology students. Journal of Homosexuality, 44(1), 121-138.

Gaertner, S.L. \& Dovidio, J.F. (2000) Reducing intergroup bias: the common ingroup identity model. Philadelphia: Psychology Press.

Gurin, P., Dey, E.L., Hurtado, S. \& Gurin, G. (2002). Diversity and higher education: theory and impact on educational outcomes. Harvard Educational Review, 72(3), 330-366.

Harrison, N. \& Peacock, N. (2010a) Cultural distance, mindfulness and passive xenophobia: Using Integrated Threat Theory to explore home higher education students' perspectives on 'internationalisation at home'. British Educational Research Journal, 36(6), 877-902.

Harrison, N. \& Peacock, H. (2010b) Interactions in the international classroom: the UK student perspective, in: E. Jones (Ed.) Internationalisation and the student voice (pp.125-42). New York: Routledge.

Hutchings, M. \& Archer, L. (2001). 'Higher than Einstein': constructions of going to university among working-class non-participants. Research Papers in Education, 16(1), 6991. 
Jaspal, R. (2015a). ESOL: an opportunity for challenging homophobia. Language Issues. Jaspal, R. (2015b). Nonheterosexual British Asian men: Social representations, identity and social relations. In J.D. Wright (ed.), International Encyclopedia of the Social and Behavioral Sciences (pp.861-866), Second Edition. Oxford: Elsevier.

Jaspal, R. \& Breakwell, G.M. (eds) (2014). Identity process theory: identity, social action and social change. Cambridge: Cambridge University Press.

Kaufman, P. (2003) Learning to not labor: how working-class individuals construct middleclass identities, Sociological Quarterly, 44(1), 481-504.

Levin, S., Sinclair, S., Sidanius, J. \& van Laar, C. (2009). Ethnic and university identities across the college years: a common ingroup identity perspective. Journal of Social Issues, 65(2), 287-306.

McDonough, P. \& Fann, A. (2007) The study of inequality. In P. Gumport (Ed.) Sociology of higher education (pp. 53-93). Baltimore, MA, Johns Hopkins University Press.

Nelson, C. (1999). Sexual identities in ESL: Queer theory and classroom inquiry. Tesol Quarterly, 33(3), 371-91.

Neimann, Y.F,, \& Maruyama, G. (2005). Inequities in higher education: Issues and promising practices in a world ambivalent about affirmative action. Journal of Social Issues, 61, 407426.

Ozga, J. \& Sukhnandan, L. (1998) Undergraduate non-completion: developing an explanatory model, Higher Education Quarterly, 52 (3), 316-333.

Reay, D., Crozier, G. \& Clayton, J. (2010). 'Fitting in' or 'standing out': working-class students in UK higher education. British Educational Research Journal, 36(1), 107-24. Reay, D. (2012). Researching class in higher education, British Educational Research Association online resource. Available online at https://www.bera.ac.uk/wpcontent/uploads/2014/02/Researching-Class-in-Higher-Education.pdf

Savin-Baden, M. (2000) Problem-based learning in higher education: untold stories. Buckingham: Open University Press.

Schmader, T., Major, B. \& Gramzow, R.H. (2001). Coping with ethnic stereotypes in the academic domain: perceived injustice and psychological disengagement. Journal of Social Issues, 57(1), 93-111.

Schweisfurth, M. \& Gu, Q. (2009). Exploring the experiences of international students in UK higher education: possibilities and limits of interculturality in university life. Intercultural Education, 20(5), 463-473.

Shook, N.J. \& Fazio, R.H. (2008). Intimate roommate relationships: an experimental field test of the contact hypothesis. Psychological Science, 19(7), 717-723.

Siemens, G. (2005). Connectivism: a learning theory for the digital age. International Journal of Instructional Technology and Distance Learning, 2(1), 3-10.

Sweller, J., Ayres, P \& Kalyuga, S. (2011). Cognitive Load Theory. London: Springer.

Thomas, L. (2002). Student retention in higher education: the role of institutional habitus.

Journal of Education Policy, 17(4), 423-442.

Thomas, L. \& Quinn, J. (2007) First generation entry into higher education. Maidenhead: Open University Press.

Trail, T.E., Shelton, J.N. \& West, T.V. (2009). Interracial roommate relationships:

negotiating daily interactions. Personality and Social Psychology Bulletin, 35(6), 671-684.

Vignoles, V. L., Regalia, C., Manzi, C., Golledge, J. \& Scabini, E. (2006). Beyond selfesteem: influence of multiple motives on identity construction. Journal of Personality and Social Psychology, 90, 308-333.

Wadell, Frei \& Martin, (2011). Professional development through inquiry: addressing sexual identity in TESOL. The CATESOL Journal, 23(1), 99-109. 
Wenger, E. (2000). Communities of Practice: Learning, Meaning, and Identity. Cambridge: Cambridge University Press.

\section{Author biography}

Rusi Jaspal is Professor of Psychology and Sexual Health at De Montfort University Leicester. He is a Chartered Psychologist and Associate Fellow of the British Psychological Society. Professor Jaspal's research focuses on social psychological aspects of self and identity and uses both qualitative and quantitative methods. He is interested in how social psychological theories can be used to enhance learning and the student experience. Rusi Jaspal is the co-editor (with Dame Glynis Breakwell) of Identity Process Theory: Identity, Social Action and Social Change (Cambridge University Press, 2014). 